\title{
Activity-Based Costing System in the Service Sector: A Strategic Approach for Enhancing Managerial Decision Making and Competitiveness
}

\author{
Ashford C. Chea \\ School of Business, Kentucky Wesleyan College \\ 4721 Covert Avenue, Evansville, IN 47714, USA \\ Tel: 1-812-471-9341 E-mail: achea@ix.netcom.com \\ Accepted: July 4, $2011 \quad$ Published: November 1, 2011 \\ URL: http://dx.doi.org/10.5539/ijbm.v6n11p3
}

Received: June 21, 2011

doi:10.5539/ijbm.v6n11p3

\begin{abstract}
The author begins the article by outlining a brief historical evolution of activity-based costing (ABC) in the USA preceded by an operating definition of terminologies. Next, he presents the literature review and the methodology employed during the study. He reviews the application of ABC in the service sector, followed by an analysis of the unique attribute of the service sector. Moreover, the researcher briefly profiles several service-oriented firms that have successfully adopted and implemented $\mathrm{ABC}$, and presents his findings from the study. He then addresses the limitations of $\mathrm{ABC}$ in the service sectors and offers strategies for dealing with these drawbacks. Finally, the researcher outlines the managerial implications of implementing $\mathrm{ABC}$ in the service sector.
\end{abstract}

Keywords: Activity-based costing, Service sector, Managerial decision making, Cost measurement

\section{Introduction}

The concept of activity-based costing (ABC) was introduced in the US, initially in the manufacturing sector during 1970s and 1980s. Robert Cooper and Robert Kaplan brought the ABC concept to light and published the body of knowledge in the Harvard Business Review in 1988. Cooper and Kaplan defined ABC method as an approach to solve the problems of traditional cost management systems; that is, the conventional cost accounting systems are often unable to identify correctly the true costs of processes. Consequently, management and quality professionals are unable to make sound decisions or make decisions based on the misrepresented data.

On the other hand, the ABC objectively assigns costs based on the cost-and-effect relationships. And in 1987, Robert Kaplan and W. Burns published in their book Accounting and Management: Field Study Perspective, the ABC body of knowledge with the initial focus on manufacturing where technology and productivity improvement have reduced the direct costs and increased indirect and overhead expenses (Narong, 2009).

\section{Definition of Terms}

An activity is an element of work to be performed to complete a project; it is a process or operation requiring time and associated resources. Activity-based costing is a total quality management tool for cost and performance measurement of activities, resources, and cost objects (i. e., products and services). ABC is also known as the" horizontal" or cross-functional cost view and can provide fact-based insight into the spending and profitability of products, services, customers, districts, distribution lines, and etc. (Narong, 2009).

Three guidelines support cost allocations in ABC.

1) Direct-cost tracing to product: The costs of flexible resources are traced to individual products that exclusively use them. The costs include direct material and direct labor costs. Some of the capacity-related costs are included that are exclusively used for one product.

2) Indirect-cost allocating to products: (a). Multipurpose resource costs -multipurpose resource costs occur when resources are consumed by multiple products. The costs are the overhead costs that need to be allocated to the products. Typically, these costs are collected in an accounting system on a yearly basis; (b). Cost centers - only the three-step allocation process uses cost centers to allocate costs of a group of consumables or indirect resources necessary to operate cost centers. Cost centers include major production machines and human resources; (c). Activity costs (cost pools): The general principle is to use separate activity costs if the cost or productivity of resources is different and if the pattern of demand varies across resources. Each activity cost is homogenous and has a cause-and-effect relationship with the cost driver. A proliferation of multiple products requires more refined activity costs to reflect the complexity of production.

3) Activity cost drivers: Cost drivers should relate to way in which activity costs are consumed. For example, setup cost is assigned to a product consuming a setup activity-based on setup time if setup time drives the costs (Park and Simpson, 2008). 


\section{Literature Review}

\subsection{The Need for $A B C$}

Traditional cost accounting, which mainly uses one single cost driver such as direct labor or output volume to allocate the overhead costs, systematically distorts product costs in modern manufacturing and service environments in which overhear costs are a significant portion of product costs. In correct product cost information can lead to poor decisions (Wang, Du, Lei and Lin, 2010).

Why is traditional accounting failing quality managers? by Gary Cokins, answers the question that the $\mathrm{ABC}$ is the solution to the conventional way of cost reporting. It bases its argument on the fact that the today's ledger systems support organizational accounting and reporting requirement but not adequate for an internal use or for a process-based decision making. The article also reveals the flaws in the standard costing system as the system is incomplete and unprocessed; misallocates indirect or overhead costs; and structurally deficient to allow decision makers to measure and analyze expenses. To illustrate his reasoning, Cokins provided side by side examples of how costs are captured, summarized and reported via the general ledger and ABC database format. The review of Why is Traditional Accounting Failing Quality Manager? proves that traditional accounting systems provide reports that make managers and quality practitioners happy or sad; however, the $\mathrm{ABC}$ methodology educate and makes them smarter in understanding the true cost of processes, products, or services (Narong, 2009).

Traditional cost-based measures were developed decade ago, when direct labor costs were valuable and accounted for a major portion of production cost. Standards were developed for tracking and controlling direct labor activity, and indirect costs were allocated across product units. Those measures were appropriate for organizations that mass produced a narrow range of products and incurred mostly variable costs. However, labor now is largely fixed and indirect costs have been a large part of total cost in most organizations. These indirect costs are incurred to acquire resources needed to provide a wide variety of activities, each with different cost drivers. Many of these indirect costs are also committed costs used to acquire capacity to perform these activities. Though management can influence the level of spending for these committed costs in the long run, the amount of capacity acquired and related spending is fixed in the short run. This can lead to either overcapacity and overspending or limited capacity and bottlenecks. Consequently, more robust systems that provide detailed, accurate information about the behavior of these costs, and that assist companies in managing these committed resources are needed. Traditional accounting has a tendency to provide information which though accurate is often late, irrelevant, and misleading. It is also complex to the uninitiated with its double entries, accruals and provisions (Gering, 1999).

An alternative managerial philosophy and its associated measurement systems, namely, activity-based costing $(\mathrm{ABC})$, has been offered to overcome some of the failures of standard costing for improving managerial decision making. $\mathrm{ABC}$ has been acknowledged to provide cost information for more precise cost allocation (Sheu, Chen and Kovar, 2003).

\subsection{Benefits of $A B C$}

The costing methodology known as $\mathrm{ABC}$ yields cost information that may be significantly different than what is provided when the traditional absorption cost method is used. Perhaps now is the time for the project management profession to consider adopting $\mathrm{ABC}$ in evaluating project profitability (Kinsella, 2002).

Moreover, $\mathrm{ABC}$ analysis enables managers to slice into the business many different ways - by product or group of similar products, by individual customer or client group, or by distribution channel-and gives them a close-up view of whatever slice they are considering. $\mathrm{ABC}$ analysis also illuminates exactly what activities are associated with that part of the business and how those activities are linked to the generation of revenues and the consumption of resources. By high-lighting those relationships, ABC helps managers understand precisely where to take actions that will drive profits (Cooper and Kaplan, 1991).

Furthermore, managers can use ABC to analyze many other aspects of their company's operations. They can compare the profits that various customers, product lines, brands, or regions generate. Then they can zero in on the dynamic of the more-or less- profitable ones. For instance, a brand analysis could look at all the expenses associated with sustaining a brand, such as "Snappy Cereal", which includes a dozen different packages and flavors. Managers can judge the brand's profitability by matching the revenues earned from all Snappy products against the expenses associated with promoting, adverting, and maintaining the Snappy brand in the marketplace (Cooper and Kaplan, 1991).

Finally, $\mathrm{ABC}$ is simple. For each process the costs buckets are identified, their cost drivers are discerned and the cost per driver is calculated. Costs are found by counting the drivers. If it costs $\$ 5$ to invoice a customer and one customer generates a hundred invoices then the associated cost is $\$ 500$. Another customer might generate ten or a thousand invoices and consequently have a cost structure which is quite different. The main work setting up an $\mathrm{ABC}$ program is identifying and calculating the cost buckets and cost drivers. This is the same groundwork required to reengineer a business, including benchmarking (how do we compare?), activity analysis (how can we do better?) and service level analysis (what will the customers pay for?). In its simplest form performance improvement can be seen in terms of time, cost, and quality. The relationship between performance improvement and $\mathrm{ABC}$ is noticeable. $\mathrm{ABC}$ has a moderate impact on time, a significant impact on quality, and a substantial impact on cost (Gering, 1999). 


\subsection{Critism of $A B C$}

Critics of $\mathrm{ABC}$ generally fell into two camps. Some argued that $\mathrm{ABC}$ was inconsistent with the principles of continuous improvement and total quality management. They wrote that $\mathrm{ABC}$ lacked customer focus, was not process-oriented, did not enhance organizational learning, and was top down in approach (i.e., did not involve employees). Other argued that $\mathrm{ABC}$ was inconsistent with the theory of constraints.

A common argument was that $\mathrm{ABC}$ could not reliably measure the short-term impact of decisions on operating costs, inventory and throughput. These criticisms reflected a misunderstanding of the purpose and nature of ABC. Early versions of $\mathrm{ABC}$ were designed to reveal strategic insight into sources of profitability. The intention of $\mathrm{ABC}$ was neither to provide day-to-day guidance on process quality nor to measure short-term variable costs (Turner, 2005)

\subsection{Unique Nature of Service Sector}

The production system in service organizations is divided into a totally invisible part and a line of visibility. The invisible part consists of such items as systems support, management support and physical support. The visible part is more or less visible to the customer who usually participates in the production process. In the invisible or interactive part, interactions between the service firm's contact persons and customers take place. The augmented service offer includes the service process and the interaction between the organization and its customers. Because services are activities or processes in which consumption is partly inseparable from production, the service production is a dynamic phenomenon by definition. The service exists as long as the production process goes on. Hence, any model of services, such as the augmented service offering and the creation of such products, must include a dynamic aspect where the basic package facilities' services and goods and support products have to be planned according to the service concept. A service, both in the elements of the basic package and in the accessibility, interaction and customer participation aspects of service production and delivery, include the desired features, which in turn creates the benefits that customers seek. Therefore, facility - sustaining expenses are dealt with best if they can be treated as an expense of operating the facility for the period and not allocated to products (Hussain and Gunasekaran, 2001).

$\mathrm{ABC}$ system have recognized that organizational resources are needed both for direct production of goods and services and for indirect or support activities. The goal of $A B C$ is to measure and then price out all the resources used for activities that generate the production of goods and services for customers (Cook, Grove and Coburn, 2000).

When analyzing production expenses in service organizations, the demand for support resources arises from product volume and mixes. In a lot of service firms including financial institutions such as banks, some expenses are driven naturally by products, e.g. checking accounts, savings, mortgages, etc. A great deal of the expenses for service functions are caused by differences in customers' preferences, even though they are using the same service. The analysis starts by examining the expense structure of each operating department and proceeds by determining the factors that create the demands for the functions performed by the department. The objective of analysis is, therefore, to discover the nature of the demand and quantify it. The basic goal of the analysis is to obtain the unit costs for processing transactions from products and customers (Hussain and Gunasekaran, 2001).

\section{Methodology}

This paper relies on the literature review of past and current relevant articles focusing on activity-based costing (ABC). Except where a source was needed specifically for its perspective on broad issues relating to firms' overall business environment, the author screened papers by "activity-based costing" and by numerous variants of keywords, focusing specifically on activity-based costing in the service sector. Source papers included refereed research studies, empirical reports, and articles from professional journals. Since the literature relating to $\mathrm{ABC}$ is voluminous, the author used several decision rules in choosing articles.

First, because $\mathrm{ABC}$ is changing fast in today's environment, the author used mostly sources published from 2000-2010, except where papers were needed specifically for their historical perspectives. Second, given the author's aim to provide a practical understanding of the main issues in $\mathrm{ABC}$ in the service sector, he included, in order of priority: refereed empirical research papers, reports, and other relevant literature on current firm $\mathrm{ABC}$ practices. To get some perspective on the current state of $\mathrm{ABC}$ in, the author begins with a brief historical perspective on $\mathrm{ABC}$.

\section{Application of $\mathrm{ABC}$ in the Service Sector}

As a technique, $\mathrm{ABC}$ has its roots in the manufacturing sector and most of the literature on $\mathrm{ABC}$ emphasizes its use in a manufacturing setting. Yet, it must be acknowledged that significant and growing economic activity takes place in the non-manufacturing sector. It is important to note that $\mathrm{ABC}$ principles apply to all types of business. For example, service companies face the same changing environment that has necessitated modifications in cost management practices in manufacturing companies in order for them to remain competitive. Strong competition for existing services together with customers requiring greater service choice will force a compression of profit margins. Since service companies are more people-intensive than manufacturing, there is greater need to focus on the myriad of activities that are performed in order to serve the customer. In a service arena, determining and lowering the "cost to serve" is a critical success factor. The challenge is to make the less expensive service also the preferred service among customers. For example, retail banks can provide basically the same service either through a cash teller or an automated teller machine (ATM). The ATM is significantly 
cheaper for banks, and generally, the preferred service option among customers. For service-oriented companies, there is urgency to use $\mathrm{ABC}$ as a growth and profit-enabling tool, through identifying and modifying non-value added activities and improving customer profitability. Although, ABC product costing information may not be acceptable for financial reporting purposes but this (negative) consideration is not relevant in the service sector due to the absence of stock valuation considerations (Clarke and Mullins, 2001).

Gone are the days when $\mathrm{ABC}$ was just for manufacturers. Nowadays, as mentioned above, it has crept into service industries such as healthcare, banking, and insurance. If a company implements $\mathrm{ABC}$, it will open a lot of eyes. More than just opening eyes, managers will be able to use the information to informed decisions (Baxendale and Dombusch, 2000).

During the last two decades, we have witnessed substantial changes in the service sector with new competitors emerging as a result of deregulation which has also given companies greater freedom in setting prices and determining the mix of products offered. Well-managed service firms with a good understanding of their markets, customers and information technologies can become much more profitable in a deregulated, more competitive environment. Even in manufacturing companies, functions such as marketing, selling, distribution, service, research and development, and general administration have become more significant expense categories than in the past (Hussain and Gunasekaran, 2001).

In service firms, the most important cost is the labor cost for personnel. Direct labor costs are traceable to the service rendered. In service organizations, the most important cost would be the professional labor involved in producing the services, i.e. the direct labor cost must be traceable to the service rendered. In addition to labor cost, various types of overhead costs will occur in any type of business. In a service firm, the overhead costs usually occur when offering a service. Consequently, they are classified as service overheads and can be compared with factory overheads in a manufacturing firm. Professional labor costs are considered service overheads rather than period cost (Clarke and Mullins, 2001).

The fallacy of the standard costing system at many companies, including service firms, is that very few customers' orders consume the same amount of resources. At a typical service firm, the profit on each sale can vary significantly. Assigning costs accurately to each account would allow the company assesses the profitability of different customers. Making customers pay for what they received is also a fairer arrangement. Few companies recover the exact cost and expenses of serving customers in the sales price charged. In many businesses, profitable accounts subsidize unprofitable ones, and management is none the wiser. In order to track costs more closely, requires the investment in more sophisticated information and accounting system such as the $\mathrm{ABC}$ system. First because it would allow management to track the profitability of each customer's account and, second, because it would allow management to track the performance of outside contractor more closely (Davis and Darling, 1996).

\section{Examples of Service -Oriented Firms That Successfully Adopted and Implemented ABC}

Financial institutions have recently been at the forefront of implementing ABC. Even though the use of ABC has evolved from original user, manufacturing companies, to services companies, the financial sector remains virgin territory. Here it is an even more elusive beast: the new frontier. While the use of $\mathrm{ABC}$ within financial institutions poses new and different challenges to $\mathrm{ABC}$ Practitioners, little knowledge or information of the experiences of implementing $\mathrm{ABC}$ in financial institutions has seeped into the public domain. This paper is aimed to highlight and discuss some issues which are particular to financial institutions, and some which are more generic to the service sector but have not been otherwise highlight.

A Large Regional Bank: The use of $\mathrm{ABC}$ to effectively allocate resources and to determine prices was the primary objective in the case of a large regional bank. Before $\mathrm{ABC}$, the bank had no clear way to cost services or determine how resources were being consumed by different activities. In addition, since some of the customers were related parties, the bank wished to show that the charges being made to them were effort-and-use-based, i.e., there was a direct correlation between the nature of service provided and the charge for this service. ABC analysis helped the bank to address both these issues - internal pricing and strategic pricing

Global Insurance Company: A global insurance company decided to implement ABC for tax purposes - that is, to determine its allocation methodology for external transfer pricing purposes. With increasing scrutiny being the norm in many of the major fiscal jurisdictions, this business wanted to ensure that its charges to its overseas affiliates were accurate and defensible to tax authorities. $\mathrm{ABC}$ ensured that the services provided to all overseas affiliates were tracked through the $\mathrm{ABC}$ systems, resulting in charges directly related to the economic benefit received by the recipient. The end result was that the Group was able to lower its effective tax rate.

Major Investment Bank: The drivers for implementing $\mathrm{ABC}$ in the global futures business of a major investment bank were both strategic decision making and internal transfer pricing. The bank had a clear need to determine which products and markets were profitable, and how it should correspondingly shape its business strategy. In this example $\mathrm{ABC}$ led to a fairly significant change in its internal transfer pricing and a dramatic improvement in its own internal performance measures. This is because $\mathrm{ABC}$ showed that the futures business had undercharged other business units in the bank for the provision of its services thereby reducing its own bottom line figures. $\mathrm{ABC}$ allowed more accurate and efficient charges to be made (Rafig and Garg, 2002)

Multifoods Distribution Group, a food-service provider in Denver. The report that ABC "kept us from bringing on new customers that we might have lost money on... Our cost to serve is based largely on our transportation 
costs, so we rank customers in terms of potential profit from zero to 250 miles, 250 miles to 500 miles, and 500 miles to 1,000 miles. Our potential for business growth is greater in rural areas, but we had to be selective because those are also the most remote areas for us to deliver".

Healthspan Transportation Service in the USA reports that, through analyzing ABC data, it was recognized that when the scheduled call service was busy, the emergency room service was often idle. As a result, the emergency room service was used to respond to scheduled calls and greater usage efficiency was achieved with a consequent (positive) impact on profitability.

For Northeast Utilities, New England's largest Electricity Utility Company, activity based measures focus on customer requirements and improving the company's market responsiveness. Improved information on the costs of maintenance, inspections, hookups, and meter readings gave managers a better idea about the level of quality and reliability customers require and how their costs of delivery of each service compare to that of their competitors. The finance manager estimates that, since the late $1980 \mathrm{~s}$, through ABC measurements, the company has eliminated $30 \%$ to $40 \%$ from its cost structure without an adverse effect on its operations.

Fair Oaks Ford, an automotive retailer in Illinois, USA had a pilot study on ABC conducted in the company. It was discovered that there were many areas in which ABC could bring significant improvements in the business. For example, a non-value added activity — waiting at the service and parts counter — was identified as being costly and this was reorganized. Further, performance measurements were developed based on cost drivers for various activities. The dealer is now in a position to determine potential opportunities for productivity improvement by benchmarking their activity performance to industry peers (Clarke and Mullins, 2001).

\section{Findings}

Findings from the author's research show that the successful implementation of ABC system within a service-oriented firm is a function of the followings: 1. The impetus of the change must come from within the organization. 2. The adoption of $\mathrm{ABC}$ must first be bought by operating manager before it is sold to top management. 3. All employees must be made to embrace ABC and be held accountable. 4. Effective sponsorship and how the rationale for $\mathrm{ABC}$ adoption is communicated to employees must be given a high priority.

Here are the steps used by the firms in this research, which can apply to any organization that wants to develop an ABC system: 1. Form a cross-functional team 2. Identify cost objects (items for which there was a need for cost information) 3. Identify activities (homogenous groups of work such as accounting) 4 . Identify cost drivers (the agents that cause costs to be incurred in the activities) 5. Attribute activity costs to cost objects and 6 . Use the information (Baxendale and Dombusch, 2000).

However, the study shows that a formidable task for most companies that implemented ABC is collecting information for specifying and assigning costs to activities. This phase involves identifying three things: 1 . What the company actually does (as opposed to its functional identification) 2. Appropriate assignment bases (resource drivers) to determine the cost of the activities, and 3. Activity drivers to assign the activity costs to cost objects (Bukovinsky, Sprohge and Talbott, 2000).

\section{Addressing the Limitations of $\mathrm{ABC}$ in the Service Sector}

$\mathrm{ABC}$ is not without its limitations, many of which relate to issues of implementations, such as: the desire to change to an $\mathrm{ABC}$ system is often met with reluctance at top-management level; problems are often encountered in identifying appropriate cost pools and related activity cost drivers; ABC implementation is costly and time-consuming. This includes, for example, the costs involved in adapting the internal accounting system with the time involvement of all staff involved in the new accounting systems; ABC systems may be too complex for the needs of the organization. Complexity is brought about by a desire to cater for a vast number of activities, cost drivers, services and cost elements. However, ABC systems that are too complex often fail to meet management requirements. It is therefore important to evaluate the scope of and role for the proposed system, if implementation is to be successful (Clarke and Tracy, 2001).

To address the shortcoming of $\mathrm{ABC}$ in the service sector, requires a performance-focused $\mathrm{ABC}$ system (PFABC) to provide an integrated $\mathrm{ABC}$ information system that can be employed 1) for performance control; 2) to solve problems associated with Traditional $\mathrm{ABC}$; and 3) to further extend the implications of conventional ABC. The PFABC is based on several steps including a) identifying major activities; b) Determining actual resources used for each activity; c) determining actual rate of each resource activity; and d)cost determination of each activity. PFABC approaches actual resource determination differently. For example, employees who perform a designated activity determine the kind and amount of the resource actually used for each activity based on its behavior or via the firm's information systems, particularly the accounting information system. The resources may be time, quantity of direct material, or other appropriate measures, but the resource must reflect a cause-effect relationship with the cost object. This provides great flexibility in choosing the appropriate resource capacity among different effective resources. This also involves a determination of the behavior of the actual resources and committed resources. The approach posits several advantages: 1) It is flexible, because other important activity driven resources such as kilograms, megabytes, or costs may be selected other than time; 2) It is based upon actual data that is usually generated by the firm's accounting system or other existing information systems. Thus, the data is objective and well documented. The details of required information that are not provided by the existing information systems can be collected directly from the employee work information, eliminating to a great extent the information asymmetry problems existing in the conventional ABC agency 
relations (Namazi, 2009).

Moreover, in the drastic competitive environment at present, single ABC cost information has not made enterprise acquire and keep long term competitive advantages and value creation ability. These research emphases of $\mathrm{ABC}$ are mainly centralized in the process producing indirect costs in the domains such as production and logistics, but it ignores the distribution process producing the indirect cost in other domain. This is the case when the enterprise evaluates the investment item or the profitability of the new product. It will find that the $\mathrm{ABC}$ method could not reflect the capital cost consumed by the investment item or the new product, and the enterprise cannot control the investment risk. Therefore, it is necessary to combine $\mathrm{ABC}$ and economic value added (EVA).

\section{Integration of $\mathrm{ABC}$ and EVA}

EVA is the economic profit of operating profit after tax minus all capital costs (including debt cost and equity cost). And it is the surplus cost minus all costs, and it is the index to measure the performance of the enterprise, and it could measure the shareholder fortune created by the enterprise. To improve the decision serviceability of the cost information of $\mathrm{ABC}, \mathrm{ABC}$ should combine with EVA. To bring the principle of EVA into $\mathrm{ABC}$ will make the cost management and the performance evaluation system more perfect and complete, and rectify the situation that $\mathrm{ABC}$ ignores the capital cost and underestimate the product cost. The combination of $\mathrm{ABC}$ and EVA will produce the so-called ABC \& EVA integrated system. The ABC module in the system emphasizes the management cost, and the EVA module emphasizes the capital cost, and the combination of both will compose a complete and effective management tool (Hu, 2010).

\subsection{Advantages of $A B C \&$ EVA Integrated System}

The integrated management mode of $\mathrm{ABC} \& \mathrm{EVA}$ has the advantages of $\mathrm{ABC}$ and $\mathrm{EVA}$, and the introduction of EVA could improve the deficiency that $\mathrm{ABC}$ could not completely reflect the capital cost, and it is very important for the management of the enterprise. Comparing with ABC or EVA, the advantages of the integrated mode include the following aspects: 1) the integrated system could distribute the cost and capitals into various activities and activity centers, and the production cost could completely reflect all costs. By introducing EVA in the cost accounting process, the integrated system could more completely reflect the cost information of product; 2) The cost information provided by the integrated system is really "complete cost" which includes not only the management cost, but the capital costs, and it is propitious to make enterprise managers realize that the capital is precious and limited resource, and they will more effectively and reasonably utilize capitals and stop or reduce the wastes of capitals $(\mathrm{Hu}, 2010)$.

Last but not least is the integration of time-based management into the $\mathrm{ABC}$ system to enhance its usefulness. Time-based management (TBM) has made process duration an important tool in performance improvement. Longer processes mean more handovers and more non-value added activities such as counting, checking, and moving. Thus although $\mathrm{ABC}$ focuses primarily on cost drivers, time is often used as a proxy for other costs, particularly once an area for improvement has been identified. This is true for bottlenecks where the lead in and out of the bottleneck are seen in terms of utilization and often apportioned based on the bottleneck drivers. TBM is both a marketing tool and a cost saving tool and is often used once ABC has targeted a performance area (Gering, 1999).

\section{Discussion}

In today's competitive environment, consumers are demanding lower priced and superior quality services while, firms are concentrating on ways to best identify their cost drivers and improve profit. Nowadays, repurchase decisions based solely on brand loyalty are becoming a thing of the past as customers do not hesitate to switch their allegiance to firms that provide excellent quality services at competitive prices. Shopping for new services on the internet has made E-commerce the new way to buy trade or sell goods. In the changing technological environment, firms have come to realize that traditional cost accounting systems do not provide accurate cost information, thus making it decisions about price, service and technology precisely wrong based on cost systems relying on accrual bases. The practice of $\mathrm{ABC}$ focuses has gained popularity because of these changing forces. $\mathrm{ABC}$ focuses on the activities associated with the costs and assigns costs by using multiple cost drivers (Stapleton et al, 2004).

The objective of this paper has been to show how $\mathrm{ABC}$ can be used as a tool for determining true costs in the service sector and help firm make better decisions based on more accurate costing information. $\mathrm{ABC}$ can assign activity costs to service, or customer that consumes resources in order to measure profitability and provide cost-effective and timely information better than traditional accounting system. ABC enables managers to understand profitability better. Making decisions related to profitability without isolating the factors accounting for profits is like playing poke without looking at one's cards.

In implementing $\mathrm{ABC}$, when determining the cost drivers for each activity, it is important that managers do not get bogged down with too many details that cannot be explained. However, a system that is too general may not be accurate enough. Customers, whether internal or external, need to be prepared for the changes to come. The firm should educate customers to prepare them before starting the implementation process. In implementing $\mathrm{ABC}$, the firm should set-up a balanced team that gets input from all parties involved: finance staff, information technology staff, human resources, so forth. The firm will be able to get faster buy-in from upper management if managers can quickly points to cost savings. $\mathrm{ABC}$ implementation must have the support of all levels in a firm. 
$\mathrm{ABC}$ requires a new way of thinking from all the firm's functions. For optimal success, the firm should establish a reasonable time frame. In most service industries, six to twelve months is aggressive but reasonable (Stapleton et al, 2004).

When applying $\mathrm{ABC}$ to service organizations, one must distinguish the different services that the organization produces. In firm producing professional services, it is probably easier to implement $\mathrm{ABC}$, as the costs are not so difficult to trace to different activities. In an accounting firm, the customers are limited, and the accountants and support people can quite easily keep record of the amount of time and material they use when dealing with a specific customer. Other professional services include consulting services, education services or legal services. For example, a consulting firm providing educational services which gives courses in service marketing will have more or less the same cost for giving the course irrespective of how many persons are attending. Unit level cost will probably be rather low, consisting of copies and similar materials distributed during the course. Most of the costs can be traced to batch-level costs, i.e. cost for teachers and rents. Cost for planning, marketing and other similar activities for a specific course can be traced to product level. Costs at the facility level can, for example, be general administration and support (Hussain and Gunasekaran, 2001).

Implementing an accounting transformation like $\mathrm{ABC}$ in the service sector only makes sense if it improves the ability of the organization to function. The impetus for change must come from within the organization. Within an organization, operating managers stand to benefit the most from $\mathrm{ABC}$. If the costs of major activities involved in a manager's operations are at the batch or product level, then the cost estimates provided to these managers will often be significantly different, and more accurate, when developed under ABC. This means that to sell $\mathrm{ABC}$ to top management, it must first be sold to the operating managers, who will benefit the most. To sell it to them, one must understand the levers they can adjust and how those levers change costs (Lere, 2002).

Moreover, for $\mathrm{ABC}$ to be successful and to produce any meaningful results, employees must be made to embrace $\mathrm{ABC}$ and be held accountable. Effective sponsorship and how the rationale for $\mathrm{ABC}$ adoption is communicated to employees are important. If this does not occur, $\mathrm{ABC}$ will be nothing but a house built on sand (Rafig and Garg, 2002).

\section{Managerial Implications}

Knowledge of the linkage between $\mathrm{ABC}$ and firm performance, as well as the organizational circumstances under which $\mathrm{ABC}$ can provide performance enhancements to companies, are essential inputs to the investment and operational decisions that companies must make before approving this important resource allocation decision. Many companies have adopted ABC, and researchers have examined important issues related to the financial impact of this organizational innovation (Maiga and Jacobs, 2008).

The central idea of $\mathrm{ABC}$ is to classify and separate activity costs from an accounting system and allocate the costs to products by measuring the cost drivers of the costs. The bottom line is that all indirect costs accumulated in an accounting system should be appropriately allocated to products consuming those indirect costs to prevent cost distortion (Park and Simpson, 2008).

There is no standard for ABC. As a result, practitioners may be familiar with different variations of ABC. Any costing approach should apply common sense. There will be environments with either low product diversity or a unique production schedule where cost measurement would be different (Vercio and Shoemaker, 2007).

\section{Concluding Remarks}

As shown in this paper, $\mathrm{ABC}$ is not only appropriate for use in a manufacturing environment; it is also most appropriate for service organizations such as financial institutions, the healthcare industry, and government organizations. In fact, some banking and financial institutions have been applying the concept for years under other names.

One of them is unit costing, which is used to calculate the cost of banking services by determining the cost and consumption of each unit of output of functions required to deliver the service. ABC in very basic terms may provide very good payback for businesses. Some of the benefits that relate directly to the financial services industry are: 1) identification of the most profitable customers; 2) More accurate product and service pricing; 3 ) Increase product profitability; 4) Well-organized process costs (Kocakulah, Bartlett and Albin, 2009).

\section{References}

Baxendale, S. J., and Dombusch, V. (2000). Activity-based costing for a hospice. Strategic Finance, 81(9), 64-71.

Bukovinsky, D., Sprohge, H., and Talbott, J. (2000). Activity-based costing for sales and administrative costs: A case study. The CPA Journal, 70(4), 70-72

Clarke, P., and Mullins, T. (2001). Activity based costing in the non-manufacturing sector in Ireland: A preliminary investigation. Irish Journal of Management, 22(2), 1-18.

Cook, T. J., Grove, H. D., and Coburn, S. (2000). ABC process-based capital budgeting. Journal of Managerial Issues, 12(3), 305-324.

Cooper, R., and Kaplan, R. S. (1991, May-June). Profit priorities from activity-based costing. Harvard Business Review, 130-137.

Davis, T. R. V and Darling, B. L. (1996). ABC in a virtual corporation. Management Accounting, 78(4), 18-24. 
Gering, M. (1999). Activity based costing and performance improvement. Management Accounting, 77(3), 24-26.

Hu, H. (2010). Primary research of the advantages and the cost control of the ABC \& EVA integrated system. International Business Research, 3(3), 141-144.

Hussain, M. M., and Gunasekaran, A. (2001). Activity-based cost management in financial services industry. Managing Service Quality, 11(3), 213-224. http://dx.doi.org/10.1108/09604520110391324

Kantor, J., and Maital, S. (1999). Measuring efficiency by product group: Integrating DEA with activity-based accounting in a large Mideast bank. Interfaces Linthicum, 29(3), 27-37. http://dx.doi.org/10.1287/inte.29.3.27

Kinsella, S. (2002). Activity-based costing: Does it warrant inclusion in a guide to the project management body of knowledge (PMBOK Guide)? Project Management Journal, 33(2), 49-56.

Kocakulah, M. C., Bartlett, J., and Albin, M. (2009). ABC for calculating mortgage loan servicing expenses. Cost Management, 23(4), 36-44.

Lere, J. C. (2002, March). Selling activity-based costing. The CPA Journal, 1-4.

Maiga, A. S., and Jacobs, F. A. (2008). Extent of ABC use and its consequences. Contemporary Accounting Research, 25(2), 533-66. http://dx.doi.org/10.1506/car.25.2.9

Namazi, M. (2009). Performance-focused ABC: A third generation of activity-based costing system. Cost Management, 23(5), 34-47.

Narong, D. K. (2009). Activity-based costing and management solutions to traditional shortcomings of cost accounting. Cost Engineering, 51(8), 11-18.

Park, J., and Simpson, T. W. (2008). Toward an activity-based costing system for product families and product platforms in the early stages of development. International Journal of Production Research, 46(1), 103-105. http://dx.doi.org/10.1080/00207540600825240

Rafiq, A., and Garg, A. (2002). Activity based costing and financial institutions: Old wine in new bottles or corporate panacea? The Journal of Bank Cost \& Management Accounting, 15(2), 12-30.

Sheu, C., Chen, M., and Kovar, S. (2003). Integrating ABC and TOC for better manufacturing decision making. Integrated Manufacturing Systems, 14(5), 433-441. http://dx.doi.org/10.1108/09576060310477834

Stapleton, D., Pati, S., Beach, E., \& Julmanichoti, P. (2004). Activity-based costing for logistics and marketing. Business Process Management Journal, 10(5), 584-591. http://dx.doi.org/10.1108/14637150410559243

Turner, P. B. B. (2005). Common cents: The activity-based costing and activity-based management performance breakthrough. New York: McGraw Hill.

Vercio, A., and Shoemaker, B. (2007, August). ABCs of batch processing: Assign the batch cost to the product that required the batch activity? Maybe not! Journal of Accountancy, 1-5.

Wang, P., Du, F., Lei, D., and Lin, T. W. (2010). The choice of cost drivers in activity-based costing: Application at a Chinese oil well cementing company. International Journal of Management, 27(2), 367-373. 